\title{
Bridge Plug Drillouts Cleaning Practices-An Overview
}

\author{
Haithem Trabelsi ${ }^{1}{ }^{*}$, Abdennour Seibi ${ }^{2}$, Ning Liu ${ }^{1}$, Fathi Boukadi ${ }^{1}$, Racha Trabelsi ${ }^{1}$ \\ ${ }^{1}$ University of Louisiana, Lafayette, USA \\ ${ }^{2}$ Utah Valley State University, Orem, USA \\ Email: `hxt5249@louisiana.edu, aseibi@gmail.com,ning.liu@louisiana.edu, fathi.boukadi@louisiana.edu, rfb2942@gmail.com
}

How to cite this paper: Trabelsi, H., Seibi, A., Liu, N., Boukadi, F. and Trabelsi, R. (2021) Bridge Plug Drillouts Cleaning Practices-An Overview. Natural Resources, 12, 19-33.

https://doi.org/10.4236/nr.2021.122003

Received: December 21, 2020

Accepted: February 7, 2021

Published: February 10, 2021

Copyright (c) 2021 by author(s) and Scientific Research Publishing Inc. This work is licensed under the Creative Commons Attribution International License (CC BY 4.0).

http://creativecommons.org/licenses/by/4.0/ (c) (i) Open Access

\begin{abstract}
Horizontal fracture-simulated completions remain the most reliable method of producing hydrocarbons from shale formations. The vast majority of unconventional wells are completed using the "Plug and Perf" method. This method involves using either a coiled tubing (CT) with a positive displacement motor or a jointed pipe to mill out composite plugs after fracturing operations are completed. An estimated average of 120,000 composite plugs is installed in the US alone each year. Bridge plug drillouts from milling operations tend to accumulate in horizontal wells and can cause stuck pipe incidents and loss of well control. Efficient removal of composite plugs' debris is crucial in achieving operational efficacies and full production potential. This paper provides an overview of the various bridge plug drillouts cleaning practices adopted in horizontal wells. It discusses several case histories, showcasing how operators solved cleanout challenges. Developed mechanistic models to better understand hole cleaning are also reviewed. As more unconventional wells are being set at more extensive depths, an economical and optimized coiled tubing process becomes increasingly important. This paper focuses on delivering a more conclusive set of recommendations to increase efficiency and improve current composite plug coiled tubing cleaning-milling practices, increase operational efficiency and reduce cost.
\end{abstract}

\section{Keywords}

CT, Horizontal Well, Bridge Plug Drillout, Hole Cleaning, Field Cases, Mechanistic Models, Research Gap

\section{Introduction}

Multiple bridge plugs are typically set at intervals to isolate stages in multistage 
hydraulic fracturing jobs in horizontal wells. Wellbore cleanout is usually performed to remove milled plug debris. In the last few decades, CT technology gained popularity, over conventional jointed-pipe snubbing with rig-assist snubbing units, for post-stimulation milling of plugs and wellbore cleanout, especially in the shale market. Well cleanouts operations are by far the most common CT service, accounting for over half of all coiled tubing operations worldwide. This technology has proven to be more reliable and cost-effective compared to the other methods. However, with the increasing demand for lateral extensive unconventional wells to expose more shale reservoir intervals and due to CT's inability to rotate like a workover rig's drill string, the Coil Tubing industry continues to work persistently to remain efficiently and economically competitive.

The cleaning techniques initially utilized in the composite plug drillouts operations are adapted mainly from the drilling and workover operations in vertical wells. These conventional techniques are continuously being adjusted to address and solve the challenges encountered in horizontal shale wells. Despite that, the focus of this discussion is geared more towards the shale market. The discussed cleaning scenarios are still applicable in both workover and post-fracturing operations. As such, the overall objective of this research is to optimize the well cleaning process by better understanding the current practices and recommend the best techniques and suggesting utilizing real-time monitoring tools and machine learning as the best ways forward.

\section{Current Field Practices}

Several studies have been conducted in the Oil and Gas industry, addressing different coil tubing cleaning challenges. This operation is complicated as its efficiency relies on many variables, including formation and completion properties, components of bottom hole assembly, motor and mill selection, type of circulating fluid, and choice of equipment.

It was indicated that most of the fracture-stimulated completions use plug n'perf. The technique requires either a connected pipe or a CT with a positive displacement motor (PDM) to mill out the composite plugs (CPs) after the fracturing maneuver is completed. In the US alone, between 100,000 to 140,000 composite plugs are set in horizontal fractured wells and milled out every year. Efficient milling is critical in order to achieve operational goals. Most of the milling operations are currently decided at the well-site, and risk assessment is only done after operational complications arise. The authors highlighted best practices after reviewing many operations across the US. The newly developed scheme used information about pre-job planning, mill design, motor selection, fluid selection, weight on bit, wiper trip frequency and speed, whether to produce the well during milling, surface flowback equipment, and operational contingencies [1].

CPs had been used for isolation in multistage stimulation for over 15 years in the US. The technique is cost-effective as hundreds of thousands of plugs are 
available to the market at competitive prices. These plugs must be removed effectively through wellbore cleanout techniques that involve milling with coiledtubing. The authors emphasized that full-scale milling tests must be performed on different plugs to optimize milling performance, particularly in tight-economic plays. The authors indicated that a millability test should involve many plugs since plugs are milled out sequentially. They added that during the experiments, real bottomhole conditions should be simulated, and millout time, penetration rate, debris size, and stump size should be measured. The authors demonstrated howmilling tests could improve the design of a plug, enhance mill selection, and improve the economics of the completion operation [2].

The Duvernay Formation in North Western Alberta contains $443 \times 10^{12} \mathrm{ft}^{3}$ of gas and $61.7 \times 10^{9}$ barrels of oil. Many laterals have been fractured to maximize the reservoir surface area to flow. Plug n' perf is the most common method used to hydraulically fracture the horizontal wells. Plugs have been milled using coiled tubing in order to initiate production. The authors explained that to optimize the milling process and maximize production, mill bits, motors, and plug designs must be investigated. They added that research and development had improved mill bit design and motor life. The disintegration of new plugs has become easy and quick [3].

Nonetheless, little research has been done on solids transport in the wellbore. Service companies have been relying on rules of thumb and experience to identify the type of gels or determine the needed number of wiper trips during milling and wellbore cleaning operations. Most milling techniques leave a substantial amount of debris that leads to stuck pipes and incur additional completion costs. The authors explained that a new method had been devised to improve plug milling efficiency. The goal was to study fluid rheology to optimize the complete milling procedure. In the paper, case histories comparing the results before and after the implementation of the state-of-the-art concept as well as project economics have been highlighted. The authors conclude that conventional practices including relying heavily on gel sweeps to clean the well are inapplicable where there is no pipe rotation and highly recommend utilizing a fluid monitoring and controlling system (FMCS) to closely examine the amount of chemicals added to the milling fluid to reduce operational costs.

Operators needed to reduce the completion cost of gas wells due to low gas market prices. For that matter, the mill out cost of composite frac plugs and frac sleeves have been lowered. Shell's Eagle Ford group has abandoned traditional milling procedures that used frequent short trips, best known as wiper trips. They incorporated an optimized fluids' system technology and an advanced bottomhole assembly (BHA) that eradicated short trips and produced cleaner wellbores. The new techniques led to a significant reduction in operational time and cost. In addition, the authors shed some light on the past CT performances and the necessity for change. They reviewed improvements made on fluid quality assurance and controls (QA/QC), changes made on CT selection, and BHA design. 
The authors indicated that these changes resulted in a substantial reduction in time and cost per well and cycle time. The changes are now the new standard for Shell's Eagle Ford CT operations [4].

It was indicated that composite plug coil-tubing drillout (CTDO) must be efficient and remain economically competitive. The author suggested that by reducing and perhaps eradicating wiper trips, CTDO could be a viable technique since less fluids and chemicals are pumped, and henceforth, pipe fatigue is reduced. This paper highlights how CT string design, bottomhole assembly (BHA), flowback arrangement, drilling techniques, fluid system, and monitoring and control can make CTDO an effective process. The author presented two case histories, where wiper trips were successfully curtailed/disregarded. The first is in the WillistonBasin. The 10,135-ft vertical and 9868 - $\mathrm{ft}$ lateral well with 24 composite plugs was drilled out by a 22,230-ft, $23 / 8$-in.-CT. The second is in the Denver-Julesburg basin. The $6780-\mathrm{ft}$ vertical and 7815 - $\mathrm{ft}$ lateral well with 39 composite plugs was drilled out with a 17,990-ft 2-in.-CT.The study recommended a more standardized drillout approach that takes into consideration flowback arrangements, drilling techniques, Bottomhole Assembly, CT string design, and continuously monitoring and controlling the operation parameters. The process has proven to be viable since the operator saved on the well intervention time [5].

Challenges to mill out composite bridge plugs (CBPs) across an over-pressured zone in a NewZealand field were discussed. While milling the plugs that isolate the over-pressured zone, the differential pressure applies substantial forces on the milling assembly that lead to buckling and possibly failure of the CT unit. A bridge plug with anequalizing path was utilized to overcome the differential pressure. During the milling process, the system indicated that pressure equalization took place. The process was monitored using a CT, real-time downhole communication unit that provided a better understanding of the downhole conditions and motor performance during the milling of plugs, thereby optimizing the operation [6].

It was also indicated that it is imperative to optimize plug milling and well cleanout techniques. They added that well cleaning continued to be a challenge due to the large number of operational variables involved. Considerable amounts of solids remain in the horizontal section of the wellbore after the cleanout is completed due to the fact that most operators use cleaning techniques that are best suited for vertical wells. This paper highlights cutting-edge cleanout procedures that utilize non-viscous fluids. Hole cleaning performance drastically improved when viscous pills were eliminated, and chemical dosage was controlled. The use of non-viscous fluids improved overall efficiency during the cleaning and milling operations from the economic and environmental viewpoints [7].

Vertical wells cleanout best practices had been applied for horizontal wells. Operators have been pumping a high volume of viscous gel sweeps and have been performing several wiper trips to remove debris from the wellbore. Recent- 
ly, to perform milling operations, CT with a larger diameter has been used due to its enhanced set-downforce and amplified annular velocities. The amount of wiper trips with larger diameter coil have been reduced, and time and money have been saved. The authors added that proper fluid rheology needs to be maintained throughout the operation. They noted that larger diameter 2-inch CT and proper cleaning fluid rheology had reduced mill out costs by $40 \%$ [8].

Raageshwari gas field was studied. The formation tops ranged from 9186 to $11,483 \mathrm{ft}$, and the reservoir is unconventional volcanic with pore pressure and temperature of 5200 psi and $284^{\circ} \mathrm{F}$, respectively. Wells were completed with a $3-1 / 2$ " tubing and a plug n' perf ( $\mathrm{PnP})$ technique was utilized in order to frac the formation. 3-1/2" 10,000-psi bridge plugs were placed between fractures and then milled with coiled tubing (CT) unit. The authors indicated that substantial amounts of gas and condensate were produced during milling. This led to increased wellhead pressures. Circulation pressure and weight on bit (WOB) were then hiked to speed up milling. Motors, unfortunately, stalled frequently and led to ineffective milling. The authors also described how optimized WOBs, penetration rates, and a newly devised milling fluid system led to increased frac fluid recovery and more considerable differential pressures across the motor. The study presented values and optimum ranges for critical parameters for efficient plug milling operations in deep retrograde gas condensate type of reservoirs. The process reduced the bridge plug milling time and saved about $5 \%$ of the well cost [9].

The experience gained from plug drillout techniques in the VacaMuerta formation in Argentina was presented. The authors analyzed drillout times, debris size and shapes, hole cleaning, and tool dull grades for different mills, roller-cone, and polycrystalline diamond compact (PDC) bits. They investigated drilling parameters, several runs to complete a well, drilled plugs per run, and tolerances regarding casing drift. They examined more than 500 plugs that were drilled out in more than 60 wells. The authors explained that to reduce drilling time, improve economics, minimize risks, and reduce CT system fatigue, the use of five to six-blade PDC bit outperformed the other tested bits. The bit minimized debris size, reduced stuck pipe risks, and improved well production [10].

A factory model that has been utilized for 3 years and has become an industry standard. The approach applies to any area irrespective of lateral length, several plugs, and reservoir measured depth. The method enhanced CT drillout routine and has been successful, repeatable, and operationally safe [11].

The results from over 200 frac-plug drillout (FPDO) and flowback operations from the United States and Argentina were presented. Positive FDPO implies that the coiled tubing injection rate is higher than annular formation flowback rates. The authors showed that monitoring flowback with a high-frequency flowmeter was a useful technique for optimizing well productivity during well cleanup. The paper also indicated that the use of a dual-energy gamma-ray multiphase flowmeter equipped with a dual-energy gamma-ray helped quantify the 
amount of debris produced during FPDO and flowback [12].

A composite frac plug was set off-depthin an unconventional shale well in the northern panhandle of West Virginia. The operator used a wireline-conveyed tractor and tractor-based milling tool to mill the plug. The authors indicated that other tubing-based solutions required more mobilization time and intricate logistics to rig down and mobilize the equipment. The tractor took only $50 \mathrm{mi}$ nutes to drive down to plug in a 1718 -ft lateral section. The authors explained that the capacity to release plugs via wireline is more economical than the tubing-based practices. These take days, sometimes weeks, to mobilize at considerable cost to operators [13].

The use of a generation four CT unit and the application of fluid rheology resulted in an efficient milling operation along a West Central Alberta horizontal well that extended for 27,379 ft. The use of heavy-walled tubing provided the required WOB for the milling operations. The use of fluid rheology applications and real-time monitoring of Reynold's number ensured downhole turbulent flow conditions. It helped optimize solid-transport and chemical consumption as well [14].

It was also stated that $\mathrm{PnP}$ is a commonly used technique for multistage fracturing procedures. The authors added that CT-assisted $\mathrm{PnP}$ operations in highpressure/high-temperature (HP/HT) wells are challenging. The "A" field in India is $\mathrm{HP} / \mathrm{HT}$ with a bottomhole temperature (BHT) of around $310^{\circ} \mathrm{F}$ and a reservoir pressure of about 9000 psi. Best practices presented in the PnP cycle included operational parameters such as CT speed, pumping rates, and bottomhole assemblies with smaller outer diameters. The parameters led to doubled operational efficiency during the maneuvers [15].

Table 1 is a summary of the current field practices' developments and findings. The table also summarizes the recommended ranges of key performance indicators (KPIs). These indicators include annular velocity (AV), Reynolds Number $(\mathrm{Re})$, cleaning gel viscosity, return rate, wiper trip times, cleaning time, and circulation rate:

\section{Lessons Learned}

In the reviewed field cases, formal training and effective communication between all stakeholders were of prime importance. It was also proposed to use a dynamic well construction workflow to predict early well performance issues and perform wellbore conditioning before setting up bridge plugs. The importance of millability tests has been emphasized. It was suggested to test at least two plugs as a pre-job routine. It was also advised to use generation four CT with larger diameter and smaller outer diameter bottomhole assemblies to improve milling performance and reduce wiper trips. PDCs with five to six-blades minimized debris size and enhanced well production. It was also recommended to utilize an early-stage fluid and flowback real-time monitoring and controlling system to reduce milling time, coil tubing, fatigue stresses, and cost. Fluid quality 
Table 1. Summary of study findings and range of KPIs.

\begin{tabular}{lll}
\hline Authors & Study Findings & Recommended Range of KPIs
\end{tabular}

Addressed efficient milling techniques and suggested pre-job computer

[1] modeling to predict achievable plug milling depth and circulating pressure to improve the cleaning operation's efficiency.

Highlighted the importance of millability tests. The authors highly

[2] recommended milling at least two plugs to allow for a more realistic evaluation of a composite plug milling performance.

Indicated the importance of closely analyzing mill bits, motors, and

[3] plug designs. The study emphasizes the significance of utilizing a fluid monitoring and controlling system to reduce milling time, Coil tubing fatigue stresses, and cost.

Eliminated short rips and produced cleaner wellbores by revising and

[4] changing the fluid quality assurance and controls (QA/QC) assessments, the selection of BHA design, and coil tubing selection. The new engineering approach resulted in a significant reduction in time and cost.

Remodeled downhole design and fluid system and made coil tubing drillout a more effective process by optimizing CT string, using low and high loadings of low shear rate viscosity fluid to effectively clean lateral and vertical sections of the wellbore during $\mathrm{POOH}$, respectively.

Used state-of-the-art bridge plugs to equalize high-pressure formations. When crossflow while perforating risk is present, the flow-through flow plugs (FFTFPs) should only be set where the pressure above is higher than the pressure below. The authors recommended using nitrified fluid when milling composite plugs set above the under pressures zone to reduce the risk of CT stuck incident due to lost circulation.

Utilized non-viscous fluids to better clean the wellbore. The method showed a substantial reduction in time and cost. The authors acknowledged that for a successful cleaning operation, the implementation of new techniques and technology should be proceeded by formal training and communication.

Used CT with a larger diameter to improve milling performance. The authors recommended single trips when possible but urged engineers and coil tubing operators to be vigilant of changing well conditions. The study concluded that wiper trips could be reduced but never eliminated due to changing well conditions.

Developed a new milling fluid system and summarized the optimum ranges of penetration rate, set-down force, and differential pressure across positive displacement motor in deep retrograde gas condensate type of reservoirs.

Explained that to reduce drilling time, improve economics, minimize risks, and reduce CT system fatigue, increasing the number of blades by using five to six-blade instead of three-blade PDC bit outperformed the other tested bits. The five- to six-blades bit minimized debris size, reduced stuck pipe risks, motor stall incidents, drillout time, and improved well production.
Wiper trip speeds range from 35 to $50 \mathrm{ft} / \mathrm{min}$.
Typical AV $=175 \mathrm{ft} / \mathrm{min}$

$\operatorname{Re}>11,500$

Linear gels with $25-30 \mathrm{cp}$

$\mathrm{AV}=300 \mathrm{ft} / \mathrm{min}$

Return rate of $3 \mathrm{bbl} / \mathrm{min}$

for 2-3/8" CT and 5" casing

AV increased from 143 to $203 \mathrm{ft} / \mathrm{min}$

Short trip decreased from 4 to 1

Time reduced from 72.2 to 25.1 hours

Slick water viscosity decreased by $21 \%$

Reynolds Number increased by $50 \%$

Viscosity in the range of 5 to $15 \mathrm{cp}$ provided maximum solids suspension for $2.375^{\prime \prime} \mathrm{CT}$ and 7" casing at $45^{\circ}$

Circulation rate ranged from $2.1-2.7 \mathrm{bbl} / \mathrm{min}$

Optimum fluid viscosity of $1 \mathrm{cp}$ Reynolds number ranged from 46,174 to 60,026

Circulation rate range of 3.0 to $3.9 \mathrm{bbl} / \mathrm{min}$ )

for 2-3/8" CT and 5.5" casing

For optimum transport efficiency,

$\operatorname{Re}>20,000$

$\mathrm{AV}>175 \mathrm{ft} / \mathrm{min}$

Fluid viscosities $<4$ centipoise

for 2" CT and 4.5" casing

Optimum circulation of $1.2 \mathrm{bbl} / \mathrm{min} \mathrm{AV}$ of 205

$\mathrm{ft} / \mathrm{min}$ lifted milling cuttings in annular space

between 1.75 " CT and 3-1/2" production tubing. 
Presented a new factory model to enhance the drillout process. The results indicated that it is imperative to optimize the critical factors influencing the plug drillout performance. Those factors were: coil tubing size, plug type, wellbore trajectory, real-time modeling, fluid rheology, and effective communication between all stakeholders.

Showed that early stage monitoring of flowback with high accuracy meters had proven to be an invaluable technique in optimizing well productivity

[12] during clean-up stages. The authors proposed that well construction workflow should be dynamic to enable predicting early well performance issues and account for relationships between various well operations.

Indicated that the use of a wireline-conveyed tractor is more efficient than tubing-based operations. The study demonstrated that wireline interventions and the ability to release plugs effectively provide the operators with a safer, faster, and more cost-effective option than the more conventional methods such as workover and coil tubing. Nevertheless, it is essential to note that this may be applicable when there are logistics issues.

Showed that the use of generation four CT and the use of fluid rheology improved cleaning efficiency. The study demonstrated that optimizing well trajectory, string design, incorporating real-time monitoring. And utilizing the advanced CT unit resulted in an ultimately very successful design.

Proposed best practices applicable in high-pressure/high-temperature (HP/HT) reservoirs. The authors stated that CT speed, pumping rates, and smaller bottomhole assemblies improve cleaning. Optimized operational parameters such as CT speed, pumping rates, and the use of smaller outer diameter bottomhole assemblies doubled operational efficiency. It is critical to perform wellbore conditioning before setting up the bridge plugs to avoid losing pressure integrity and possible damage to the sealing element.
Optimum cleaning conditions:

pump rate $=4 \mathrm{bpm}$

$\mathrm{AV}=258 \mathrm{ft} / \mathrm{min}$

for $2-3 / 8$ " CT and 5 "-casing

$\mathrm{AV} \geq 200 \mathrm{ft} / \mathrm{min}$

for CT sizes 2-3/8" and 2-5/8" and casing sizes 5"

and 5.5”

Optimum AV = $190 \mathrm{ft} / \mathrm{min}$

Optimum circulation rate $=1.8 \mathrm{bbl} / \mathrm{min}$

Clean out time $=720 \mathrm{~min}$

Circulation pressure $=6000 \mathrm{psi}$

assurance and controls (QA/QC) assessments and coil tubing selection should be revised. It was also suggested to use non-viscous fluids for better cleaning performance. Some other practices recommended the use of a wireline-conveyed tractor over tubing-based operations.

Furthermore, data analytics' studies conducted to improve and better understand hole cleaning in horizontal wellbores are presented in the next section.

\section{Mechanistic Models}

Many authors ([11] [16]-[23]) used data analysis to better understand and optimize hole cleaning operations.

Based on the Buckingham- $\pi$ theorem, several dimensionless groups were defined and a semi-empirical correlation to predict the critical deposition velocity was developed. As shown in Equation (1), velocity in the open area above the bed was assumed to be the same as the critical velocity [16]. 


$$
V_{s}^{0}=v_{\text {open }}
$$

where, $V_{s}^{0}$ is initial cuttings volume remaining in the wellbore annulus and $v_{\text {open }}$ is the in-situ liquid velocity in the open area above which is the used circulating cleaning velocity.

The authors also predicted hole cleaning time $(t)$, when circulating, as:

$$
t=\frac{V_{s}^{0}}{C^{0} q_{l}} \ln \left(\frac{V_{s}^{0}}{V_{s}}\right)
$$

where, $C^{0}$ is the initial cleaning concentration, $q_{l}$ is the circulated mud flow rate, and $V_{s}$ is the total cuttings volume remaining in the wellbore annulus.

The optimum cleaning speed ( $v_{\text {optimum }}$ ) was defined as:

$$
v_{\text {optimum }}=\frac{C q_{l}}{(1-C) C_{b} A_{b}}
$$

where, $C$ is the cuttings pick-up capacity, $C_{b}$ is the cuttings volume concentration in the bed, and $A_{b}$ is the cuttings bed cross-sectional area.

A hole cleaning model for CT operations was also developed [17]. The model was used to determine the maximum flow rate the CT can deliver and the specific annular liquid velocities using flow friction, bottomhole pressure, and configuration of the work string.

Additionally, a mathematical model for solid-liquid flow at low velocities for different configurations of horizontal and eccentric annuli was published [20]. The authors defined the parameters that affect the critical velocity given by:

$$
v_{c}=f\left[d_{p}, d_{1}, d_{2}, h_{b}, C_{v},\left(\rho_{s}-\rho_{l}\right) g, \rho_{l}, \mu_{l}, \beta, H_{L}, \varepsilon\right]
$$

where, $d_{1}$ is drillpipe diameter, $d_{2}$ is openhole diameter, $C_{v}$ is cuttings volume concentration, $\mu_{l}$ is mixture viscosity, $\beta$ is wellbore inclination angle from vertical, $H_{L}$ is liquid holdup, and $\varepsilon$ is eccentricity of drillpipe.

Furthermore, a one-dimensional unsteady-state two-phase mechanistic model of cuttings transport with foam was developed [22]. The authors introduced a new critical deposition velocity correlation for foam-cuttings flow. The model is solved numerically to predict cuttings bed height as a function of drilling rate, gas and liquid injection rates, rate of gas and liquid influx from the reservoir, and borehole geometry. Other foam modeling efforts in horizontal wells have also been highlighted ([18] [19] [21]).

To study variation in downhole tool data and optimize the procedure, realtime data analysis was utilized [11]. Technology implementation helped remove unnecessary short trips and eliminated stuck coiled tubing unit operations. As a result, more than 320 horizontal wells with a depth ranging from 5000 to 10,000 $\mathrm{ft}$ have been successfully achieved. Sixty percent of the completion time and sixty-one percent of the cost were saved.

Besides, post drillout data in the Permian Basin and the Eagle Ford was analyzed [23]. The authors used 63 wellbores completed with 2664 composite plugs, 60 wellbores used a combination of 382 dissolvable and 1792 composite plugs, 
and 16 wellbores completed with 543 dissolvable plugs. The intent was to correlate key performance indicators (KPIs) such as time in well, average milling time, wash time, plug spacing, and the total number of plugs with well geometry, lateral length, and plug type. Statistical analysis indicated that the overall procedure time when plugs were combined was reduced by $46 \%$ compared to that spent on dissolvable plugs only. Data analysis also showed that at least $45 \%$ of dissolvable plugs did not dissolve, and CT intervention was required. Table 2 summarizes study findings in the area of hole cleaning model development.

\section{Well Cleaning Best Practices}

Best practices indicated that KPIs like circulation rate, fluid viscosity, annular velocity, and Reynolds' number impact wellbore cleaning efficiency. Optimum circulation rate ranged from 2.1 to $4 \mathrm{bbl} / \mathrm{min}$ depending on the size of the CTcasing pair. Viscosity in the range of 5 to $15 \mathrm{cp}$ provided maximum solids suspension. Typically, annular velocities in the range of 143 to as high as $300 \mathrm{ft} / \mathrm{min}$,

Table 2. Summary of study findings.

\begin{tabular}{|c|c|}
\hline Authors & Study Findings \\
\hline$[16]$ & $\begin{array}{l}\text { Closely studied cuttings transport and hydraulics of foam in horizontal and highly } \\
\text { deviated wellbores Predicted cuttings critical deposition velocity. The author } \\
\text { developed a mechanistic model that describes cuttings transport with foam. The } \\
\text { study proposed additional methods to calculate the cuttings bed thickness. }\end{array}$ \\
\hline$[17]$ & $\begin{array}{l}\text { Developed a hole cleaning model for coiled tubing operations using foam } \\
\text { correlations. The model was used to determine the anticipated velocities, } \\
\text { pressures, and rates. }\end{array}$ \\
\hline$[20]$ & $\begin{array}{l}\text { Developed model for cleaning wellbores with different well configurations and } \\
\text { eccentric annuli. The model predicted the bed height for a range of inclination } \\
\text { angles at various operating conditions. The authors developed a deposition velocity } \\
\text { correlation that can determine the thickness of the cuttings along the wellbore. }\end{array}$ \\
\hline [22] & $\begin{array}{l}\text { Numerically analyzed the cuttings transport in horizontal wells with foam as the } \\
\text { carrying fluid. The new critical foam velocity correlation determines the } \\
\text { minimum foam flow rate required to remove cuttings from the highly } \\
\text { deviated sections of the wells. }\end{array}$ \\
\hline $\begin{array}{c}{[18][19]} \\
{[21]}\end{array}$ & $\begin{array}{l}\text { The authors highlighted foam modeling efforts in horizontal wells. The Herschel } \\
\text { Bulkey number }(\mathrm{Hb}) \text { can be a good indicator of the ratio of the final weight of } \\
\text { particles removed from the deviated section of the pipe to the initial weight of } \\
\text { particles (HCE). This number considers the velocity profile of the fluid and its } \\
\text { rheology. The design of drilling fluids by using the value of } \mathrm{Hb} \text { is more justifiable, } \\
\text { especially for fluids with a high shear rate. }\end{array}$ \\
\hline$[11]$ & $\begin{array}{l}\text { Analyzed real-time data to improve the cleaning procedure by identifying trends in } \\
\text { data obtained from downhole tools. A road map was created by optimizing critical } \\
\text { factors that directly influence coil tubing plug drillout procedures. The engineering } \\
\text { approach provided successful, consistent, and repeatable outcomes. }\end{array}$ \\
\hline [23] & $\begin{array}{l}\text { Used statistical analysis to correlate KPIs with operational variables. The study's } \\
\text { goal was to present the operators with an assessment tool to evaluate the benefits } \\
\text { and costs of various plug technologies, providing the best strategic placement to } \\
\text { execute interventions safely and effectively. }\end{array}$ \\
\hline
\end{tabular}


depending on the size of the CT-casing pair, and Reynolds' number above 20,000 ensured optimum transport efficiency.

The paper review was also used to identify research gaps in the areas of realtime monitoring and data analysis, data analytics, and machine learning.

\section{Research Gap Identification}

\subsection{Real-Time Monitoring Tool}

Recently, real-time cuttings' monitoring tools have added immense advantages to hole cleaning operations. These tools, however, remain simplistic, and wellbore in-situ conditions need to be embedded in their design.

\subsection{Data Analytics and Machine Learning}

Data analytics is a discipline used to find patterns, trends, and anomalies lying within data to predict future performance and thus deliver the insights needed to drive evidence-based decision making. In contrast, machine learning is a branch of artificial intelligence that automates analytical model building utilizing algorithms, learning from data to improve desired tasks' performance without being explicitly programmed. It finds probabilistic laws and statistical regularities based on the observed data to define the physical process. Promising research has proven its value thanks to the use of data generated during drilling and completion operations [24]. Operators have also produced a significant amount of data during bridge plug cleanouts. These data banks can be harvested to provide input for machine learning algorithms to accurately predict and optimize bridge plug cleanout operations' future performance.

\section{Conclusions}

Important advances had been made in the area of bridge plug cleaning techniques. In the discussed case histories, cleaning techniques for bridge plug drillouts came a long way. Operators are drifting away from vertical well cleaning techniques to adapted techniques for horizontal wells. Case histories indicated that the use of a fourth generation CT unit is a viable solution compared to jointed pipe. The method provided more WOB and reduced buckling problems. More advanced bridge plugs have also been used. Research showed that milling bridge plugs is more efficient than soluble plugs. The use of rheology and realtime monitoring has also led to better cleanout performance.

A significant research gap exists in the area of bridge plug drillouts' cleaning model development. Despite the fact that an immense data base for hole cleaning exists, attempts made in the development of a hole cleaning coefficient remains insignificant because of the complexity and lack of understanding of the physics of the cuttings transport problem.

The way forward is to use data analytics and machine learning using python as a coding language to develop empirical models that can be used to predict hole cleaning efficiency. 


\section{Availability of Data and Materials}

The data supporting the conclusions of this paper are included within the paper. Any queries regarding these data may be directed to the corresponding author.

\section{Consent for Publication}

The authors have agreed to submit it in its current form for publication in the journal.

\section{Competing Interests}

The authors declare that they have no competing interests.

\section{References}

[1] Craig, S., Harris, J., Lehr, D. and Brandt, N. (2012) Best Practices for Composite Plug Milling. SPE/ ICoTA Coiled Tubing \& Well Intervention Conference \& Exhibition, The Woodlands, 27-28 March 2012, SPE Paper No. SPE-154060-MS. https://doi.org/10.2118/154060-MS

[2] Cromer, C.M., Aviles, I. and Li, N. (2014) Composite: Is Multi-Plug Milling That Fast? SPE/ICoTA Coiled Tubing \& Well Intervention Conference \& Exhibition, The Woodlands, 25-26 March, SPE Paper No. SPE-168301-MS. https://doi.org/10.2118/168301-MS

[3] Huynh, D., Medvedev, O., Hamid, S. and Anas, Y. (2014) Composite Plug Milling Efficiency Improvement through Rheology Control-Lessons Learned from the Horizontal Completions in the Duvernay Shale. SPE Annual Technical Conference and Exhibition, Amsterdam, 27-29 October 2014, SPE Paper No. SPE-170738-MS. https://doi.org/10.2118/170738-MS

[4] Pawlik, M., Champagne, J., Whitworth, J. and Trebing, C. (2014) Optimizing Frac Plug Mill Outs in Horizontal Wells using Coiled Tubing. SPE/ ICoTA Coiled Tubing \& Well Intervention Conference \& Exhibition, The Woodlands, 25-26 March 2014, SPE Paper No. SPE-168279-MS. https://doi.org/10.2118/168279-MS

[5] Ahn, J. (2015) Achieving Economically Successful Coiled Tubing Composite Plug Drillouts in Extended Reach Wells. SPE/ICoTA Coiled Tubing \& Well Intervention Conference \& Exhibition, The Woodlands, 24-25 March 2015, SPE Paper No. SPE173665-MS. https://doi.org/10.2118/173665-MS

[6] Li, Y., Terry, A., Parr, C., Stanley, R. and Dunsmore, B. (2015) Using Coiled Tubing to Safely and Efficiently Mill Out Composite Bridge Plugs Set Across Zones with Significant Differential Pressures. SPE/ICoTA Coiled Tubing \& Well Intervention Conference \& Exhibition, The Woodlands, 24-25 March 2015, SPE Paper No. SPE173671-MS. https://doi.org/10.2118/173671-MS

[7] Cano, V., Cardona, W.G., Murphy, C. and de Araujo, M. (2016) Improved CT Well Cleanout and Milling Procedures Utilizing Only Non-Viscous Cleanout Fluids. SPE/ ICoTA Coiled Tubing \& Well Intervention Conference \& Exhibition, Houston, 22-23 March 2016, SPE Paper No. SPE-179070-MS. https://doi.org/10.2118/179070-MS

[8] Snyder, E. and Noland, J. (2016) Optimization of Single Trip Milling Using 2-Inch Coiled Tubing. SPEI ICoTA Coiled Tubing \& Well Intervention Conference \& EXhibition, Houston, 22-23 March 2016, SPE Paper No. SPE-179090-MS. https://doi.org/10.2118/179090-MS

[9] Vijayvargia, U., Tiwari, S., Anand, S., Sidharth, P., Sharma, A., Manish, K., Yadav, J. 
and Goyal, R. (2016) Optimized Coiled Tubing Based Milling of Multiple Composite thru Tubing Bridge Plugs in High Condensate Hydraulically Fractured Deep Gas Wells-A Case Study. International Petroleum Technology Conference, Bangkok, 14-16 November 2016, IPTC Paper No. IPTC-18728-MS. https://doi.org/10.2523/IPTC-18728-MS

[10] Zanellato, G., Szklarz, J.M., Pach, E. and Nebiolo, M. (2017) Fracturing Plugs Drillout Experiences in Unconventional Applications. SPE/ICoTA Coiled Tubing \& Well Intervention Conference \& Exhibition, Houston, 21-22 March 2017, SPE Paper No. SPE-184765-MS. https://doi.org/10.2118/184765-MS

[11] Barraza, J., Champeaux, C., Myatt, H., Lamon, K., Bowland, R., Bishop, T., Noles, J. and Garlow, R. (2018) Factory Model Approach for Successful Coil Tubing Unit Drillout Operations in Unconventional Horizontal Wells. 2018 SPE Annual Technical Conference and Exhibition, Dallas, 24-26 September 2018, SPE Paper No. SPE-191689-MS. https://doi.org/10.2118/191689-MS

[12] Potapenko, D., Theuveny, B., Williams, R., Moncada, K., Campos, M., Spesivtsev, P. and Willberg, D. (2019) State of the Art of Flow Management for Frac Plug Drillout and Flowback. SPE Annual Technical Conference and Exhibition, Calgary, 30 Sepember-2 October 2019, SPE Paper No. SPE-196084-MS. https://doi.org/10.2118/196084-MS

[13] Comer, A. and Alferez, O. (2019) Composite Plug Milling via Wireline Reduces HSE Risks and Logistics on Location. SPE Eastern Regional Meeting, Charleston, 15-17 October 2019, SPE Paper No. SPE-196584-MS.

https://doi.org/10.2118/196584-MS

[14] Yekta, Y., Stang, B., Hilling, S., Schwartz, C., Cheung, B., Elliott, K.J. and Williams, C.D. (2020) A Success Story: Utilizing Different Variables in Design and Execution of Coiled Tubing Extended Reach Milling Operations. Proceedings of SPE/ ICoTA Well Intervention Conference and Exhibition, The Woodlands, 24-25 March 2020, SPE Paper No. SPE-199802-MS. https://doi.org/10.2118/199802-MS

[15] Singh, I., Saraf, A., Pathak, A.R., Bandyopadhyay, B., Dehingia, M., Wijoseno, D.A., Shaik, M. and Rao, D.P. (2020) Best Practices for Using Coiled Tubing to Assist Plug-and-Perf Multistage Fracturing Operations in HP/HT Wells. Offshore Technology Conference, Houston, 4-7 May 2020, OTC Paper No. OTC-30532-MS. https://doi.org/10.4043/30532-MS

[16] Larsen, T.I. (1990) A Study of the Critical Fluid Velocity in Cuttings Transport. MS Thesis, University of Tulsa, Tulsa.

[17] Nguyen, D. (1997) Mathematical Models of Cuttings Transport \& Drilling Fluid Displacement by Cement Slurry in Horizontal Wells. Ph.D. Dissertation, University of New South Wales, New South Wales.

[18] Saintpere, S., Marcillat, Y., Bruni, F. and Toure, A. (2000) Hole Cleaning Capabilities of Drilling Foams Compared to Conventional Fluids. SPE Annual Technical Conference and Exhibition, Dallas, October 2000, SPE Paper No. SPE-63049-MS. https://doi.org/10.2118/63049-MS

[19] Martins, A.L., Lourenço, A.M.F. and de Sa, C.H.M. (2001) Foam Property Requirements for Proper Hole Cleaning While Drilling Horizontal Wells in Underbalanced Conditions. SPE Asia Pacific Oil and Gas Conference and Exhibition, Brisbane, October 2000, SPE Paper No. SPE-64382-MS. https://doi.org/10.2118/64382-MS

[20] Li, J. and Walker, S. (2001) Sensitivity Analysis of Hole Cleaning Parameters in Directional Wells. SPE Journal, 6, 356-363. https://doi.org/10.2118/74710-PA

[21] Ozbayoglu, E.M., Miska, S.Z. and Reed, T. (2003) Cuttings Transport with Foam in 
Horizontal and Highly Inclined Wellbores. SPE/IADC Drilling Conference, Amsterdam, February 2003, SPE Paper No. SPE-79856-MS.

https://doi.org/10.2118/79856-MS

[22] Li, Y. and Kuru, E. (2004). Prediction of Critical Foam Velocity for Effective Cuttings Transport in Horizontal Wells. SPEI ICoTA Coiled Tubing Conference and Exhibition, Houston, March 2004, SPE Paper No. SPE-89324-MS.

https://doi.org/10.2118/89324-MS

[23] Meza, G.G., Alarcon, X.B. and Loundy, R. (2020) A Detailed Evaluation of Coiled Tubing Drillouts of Composites and Dissolvable Plugs in Permian Basin and Eagle Ford Fields. SPE/ICoTA Well Intervention Conference and Exhibition, The Woodlands, 24-25 March 2020, SPE Paper No. SPE-199790-MS. https://doi.org/10.2118/199790-MS

[24] Motamedi, M. and Farshad, F.J. (2020). An Overview on Applications of Machine learning in Petroleum Engineering. 3rd International Congress on Science and Engineering, Hamburg, March 2020. 


\section{Nomenclature}

$A_{\text {annular }}=$ annular area, $\mathrm{m}^{2}$

$A_{b}=$ cuttings bed cross-sectional area, $\mathrm{m}^{2}$

$C=$ cuttings pick-up capacity, in decimal

$C^{0}=$ initial cuttings concentration, in decimal

$C_{b}=$ cuttings volume concentration in the bed, assumed as 0.52

$C_{b}=\frac{A_{b}}{A_{\text {annular }}} \times 100 \%$, the bulk volume concentration in the annular test section,

percentage

$C_{v}=$ cuttings volume concentration, cuttings true volume/(cuttings true volume + mud volume), $\%$

$d_{P}=$ particle diameter, $\mathrm{m}$

$d_{1}=$ drill pipe diameter, $\mathrm{m}$

$d_{2}=$ openhole diameter, $\mathrm{m}$

FTFPs = flowthrough frac plugs

$g=$ acceleration caused by gravity, $\mathrm{m} / \mathrm{s}^{2}$

$h_{b}=$ bed height, $\mathrm{m}$

$H_{L}=$ liquid holdup, in decimal

$q_{l}=$ circulated mud flow rate, $\mathrm{m}^{3} / \mathrm{min}$

$t=$ time, seconds

$v_{\text {open }}=$ in-situ liquid velocity in the open area above, $\mathrm{m} / \mathrm{s}$

$v_{\text {optimum }}=$ optimum cleaning speed, $\mathrm{m} / \mathrm{min}$

$V_{s}=$ total cuttings volume remained in the wellbore annulus, $\mathrm{m}^{3}$

$V_{s}^{0}=$ initial cuttings volume remained in the wellbore annulus, $\mathrm{m}^{3}$

$\mu_{l}=$ viscosity of mud or mixture viscosity of gas and liquid, Pa.s.

$\rho_{l}=$ liquid density, $\mathrm{lbm} / \mathrm{gal}$

$\rho_{s}=$ solid density, $\mathrm{lbm} / \mathrm{gal}$

$\beta=$ wellbore inclination angle from vertical; $90^{\circ}$ refers to the horizontal position

$\varepsilon=$ eccentricity of drill pipe, $\frac{2 \chi}{d_{2}-d_{1}}$, in decimal 